\title{
Open Classes to Local Communities: A Reflection Analysis of a School Environmental Project
}

\author{
Maria Kalathaki* \\ School Advisor for Secondary Science Teachers of West Crete, Regional Educational Directorates of Crete, Greece
}

*Corresponding Author: kalathakimaria.edu@gmail.com

\section{ABSTRACT}

School projects of environmental education promote discovery learning, through teamwork, by involving local communities, scientists, organizations, authorities, and bodies and are carried out largely online in virtual environments. This research aimed to identify and highlight those characteristics of local communities that can be exploited by opening them up to classes with activities that are matched in experiential and inquiry teaching and learning. Specifically, through the frame of education for sustainable development. This research required the development of a tool for the reflection analysis of environmental open classes in local communities with the open classes' learning environments and those components of learning environments, which support the inquiry teaching and learning procedure in a school environmental project. Teachers supplied students with focused questions and urged them to try to find their own answers. More specifically, teachers facilitated students as coresearchers to choose their own issues, to set the queries, and decide the best methods to conduct their inquiry. This research demonstrates how open classes in social learning environments, offered experiences to students and teachers bringing them face to face with questionnaires, evidence, historical knowledge and real problems, which had been missing from their previous learning and teaching experiences.

KEY WORDS: education for the sustainable development; school environmental projects; open classes

\section{INTRODUCTION}

E nvironmental education (EE), in the transformation to education for sustainable development (ESD), opens schools up to society by expanding communication, developing partnerships with local authorities and institutions, involving parents and specialists, through information and communication technologies (ICTs) use (Greek Ministry of Education, 2007; Vare and Scott, 2007). School projects of environmental education promote discovery learning, mainly through teamwork, by involving local communities, scientists, organizations, authorities, and bodies online and in virtual learning environments (Frey, 1986; Mandrikas et al., 2005). Usually, the school environmental teams undertake to study a local issue with an interdisciplinary approach (Chrisafidis, 2006; Zygouri, 2005).

The purpose of the Open Environmental Classes programme "Callisto," which was implemented in the 2007-2008 school year by the Greek Ministry of Education in Secondary Education, was the special communication relationship between teachers and students in an active learning process in such environments that gave students the impulse for seeking experiential knowledge through teamwork and action (Callisto, 2008). Open classes position the lessons as events that built upon typical school classes for and with the students, inside and outside the school, with the teachers, scientific collaborators, bodies, institutes, and authorities. The results of intergenerational work in local communities are very promising as children, adults, schools, communities, and the environment benefit from this type of collaboration, by giving important lessons to all (Gallagher et al., 2000). The theoretical approach of teaching concepts becomes experiential with educational visits by student groups and accompanying teachers, to places of special environmental and ecological interest. Through these visits, students and teachers continue their school-based education that has been adapted to the environmental specificities of the visited region as well as enriched with cultural, traditional, and leisure activities to acquire comprehensive education (Callisto, 2008). These visits are very well-designed activities of EE with predetermined achievable learning objectives that strengthen the environmental concepts; and cultivate ecological values, attitudes, and behaviors.

This research aimed to identify and highlight those characteristics of local communities that can be exploited by opening them up to school classes with activities that are matched in experiential and inquiry teaching and learning through the frame of ESD. Specifically, this research draws attention to the implementation of a SPEE of Meleses Lyceum of Crete during the school year 2007-2008 with the subject "forest, biodiversity, and quality of life" as a reflection analysis of the project specifying those characteristics of indoor and outdoor learning environments which must be taken into consideration when school classes are opened in local communities. 


\section{LITERATURE REVIEW}

An individual's cognitive processes and development depends on the social space in which human activities are happening as well as the nature of the problems that learners are invited to resolve (Doise and Mugny, 1984; Komis, 1999). Inquiry is fundamental to make students start thinking more like scientists, that is, to acquire "critical thinking" abilities. The problem that teachers seem to have is the lack of time to cover the whole curriculum, which is the reason why many use inquiry to teach only part of the content, or to develop exclusively a limited number of laboratory experiments. For this reason, history is not easily included into inquiry experiences of natural sciences, and as a consequence, the nature and history of science becomes difficult to be taught (Espinosa-Bueno et al., 2011).

Implicit knowledge is determined by the social context where learning is acquired and through the interactions within the learner's background. Educational activities facilitate the process of learning if they are well-designed and fitted to the group that they address. According to Bruner (1960), everything can be taught if it can be offered in an appropriate way, suitable to be realized, and absorbed by each learner and group, in individual and team learning procedure. Team cooperation learning can be achieved, even in nonhomogeneous groups, if they address a specific topic to discover a subject, to produce a result, present, and evaluate it (Kartsiotis, 2008). The construction of knowledge is based on the individual activity of the learner, the adult mediation, the offer of favorable conditions for learning, the use of language, and symbolic forms of communication and representations. These generally depend on the role of social environment (Komis, 2004). For this, modern learning environments must be designed to facilitate active and collaborative learning processes, to help students understand and not memorize, promote change in their ideas and bridge the gap between the activities that take place in the school and those that are authentic cultural actions in the society.

\section{METHODOLOGY}

As students of Lyceums are only one-step away from adulthood, it is useful to identify and highlight those significant components of an educational project, which aim to teach them about the way of discovering their environment. This research aimed to identify those characteristics of the learning environments that supported efficiently experiential and inquiry learning outside the school classrooms. To highlight the areas and characteristics of the learning environments for open classes in society, a content analysis of the archival material of the project "forest, biodiversity, and quality of life" was carried out. This included a critical analysis of the research themes and questions, accurate determination of the research sources and selection of the archival material of the research, as well as the application form (AF) and final report (FR) of the project. The aims, actions, activities, and process of the school environmental project retrieved from the archival material along with the interviews of the three teachers involved, ensured the triangulation of data, and results (Bell, 1997). The sentence and paragraph were used as the basic conceptual unit to serve the needs of the content analysis (Cohen and Manion, 1994; Iosifidis, 2003; Iosiphides and Spyridakis, 2006).

The research was carried out with the use of the "tool for the reflection analysis of environmental open classes to local communities" (Table 1). This was designed on the basis of two Tools for the evaluation of applying the discovery teaching method (DTM) in the Greek environmental school projects through the prism of education for the sustainable development, taking also into consideration the aims of "Open Classes Callisto" Program of The Greek Ministry of Education (Callisto, 2008; Kalathaki, 2013; Kalathaki, 2015).

In the applied axial coding, the categories were created corresponding with the queries and hypotheses which had been set in the beginning. The management of data utilized the technique of continuous comparison to impose some kind of order and organization to reveal meanings and categories with structure, classification, and sorting data before analysis.

The content of printed and digital material was examined thoroughly. Discourse analysis looked for the 26 components/ characteristics of learning environments that comprise the seven main categories of open classes to local communities (Kalathaki, 2013; Kalathaki, 2015). During the study of the research material, every phrase, paragraph, figure, photo, etc., was recorded and coded into the seven categories: Cyberspace, classrooms, laboratory of natural sciences, library, field, schoolmates' companies, and local communities, which supported the inquiry teaching and learning procedure in a school environmental project (criteria) contained in Table 1.

\section{FINDINGS}

\section{In the Cyberspace, Using ICTS}

Nowadays, almost all secondary and higher education students have embraced social networking as a key part of their lives. Furthermore, learners use social networking technologies for academic purposes such as conducting group work. Research has established how social networking technologies improve learners' technology proficiency, enhance learners' social skills, and help them to communicate in new ways with new people (Zanamwe et al., 2013). This was noted by one of the teachers in the study, "the teams used a variety of software for general use, such as image processing software, word processor, spreadsheets, and utilization of multimedia applications to manage their electronic material and present the project results" (Teacher 2).

\section{In the Classrooms}

The effectiveness of educational projects is seen by the fact that most of what someone learns does not come from school, that is the lessons, but from the free participation in activities of a telltale content, close to his/her interests, and experiences (Rogers, 1998). In the period of project implementation, the school 


\section{Table 1: Tool for the reflection analysis of environmental open classes to local communities}

\begin{tabular}{ll}
\hline Open classes' learning environments & Components of learning environments which support the inquiry teaching and \\
learning procedure in a school environmental project
\end{tabular}

A. Information and Communication Technologies (IC
B. Inside the Classrooms

C. Laboratory of Natural Sciences

D. Libraries of Printed and Digital Content

1. PC centralized technologies (Hardware, Software, Multimedia, websites, and web-services)

2. Phones centralized technologies (Smart Phones, Fax, SMS, Emails, Facebook, etc.

1. Thematic areas of the school curriculum linked to the Project's subjects

2. Communication with universities, institutions, organizations, and consultation by experts

3. Lessons with discussions, lectures, presentations, readings, round tables, peer learning activities, etc.

1. School experiments of Physics, Chemistry, Biology, and Geology

2. Constructions with natural materials collected from the fields

3. Collection and development of specific devices and educational material for analyses etc.

4. Virtual experiments and applications related to the studied subject

1. Live and virtual navigation of school, municipal, and online libraries for the bibliographic research of the project theme

2. Use of the teachers' and families' educational material of university and school lessons

3. Search in "Photodenro" depository of school educational material of the Greek Ministry of Education

4. Investigation of the project's subject in the textbooks

E. In the Field

1. Measurements, observations, and recordings

2. Educational visits to museums, areas of ecological, archeological, and cultural interest

3. Participation to educational programs offered by the environmental centers

4. Design and engraving of educational pathways in natural areas with special cultural interest

5. Discussions with scientists, bodies, and authorities with suggestions for environmental problem solving and development policies

F. The schoolmates' Company

1. Exploitation of friendships

2. Hope for change

3. Living together and sharing common interests

G. With Local Communities

1. Connections of the project's subjects to the daily life and the improvement of the quality of life

2. Different points of view of the issues by giving local, national, global dimensions to the project's topics

3. Interdisciplinary approach of the project subject by investigating it in the local historical and social context

4. Intergenerational communication and collaboration

5. Participation to Lifelong Learning Programs funded by European Union and Greek State curriculum was augmented with project topics to include both indoor and outdoor activities. These augmentations supported all participants in an effort to be involved in the whole class, not only the environmental team. One of the participating teachers commented on this:

Teachers made use of didactic modules in the courses that they teach, so all the students of the school met the subject matter of the project by developing discussions inside the classrooms, in the period of the materialization of the project (Teacher 1).

Teaching should be consistent with the nature of scientific inquiry, and as Rutherford and Ahlgren (1991) proposed, teaching of science and technology has to be carried out according to the following steps. Start with questions about the nature, then motivating students to be involved, and then, focusing on the collection and use of evidence, after than providing historical contexts and perspectives, then insisting on clear expression, and then, using the team approach, and finally conquering of the new knowledge through discovery. "These steps, in general, tried to be followed in the classrooms when investigated some project issues" (Teacher 3).
This study's project had all the characteristics of the "New School Curricula" developed during the Greek Educational Reforming of 2010 (New School, 2010). It was "targetcentralized" because it proposed goals relating not only to building knowledge but also to develop skills and desirable attitudes. It was "digital" because it satisfactorily integrated ICTs to achieve specific learning objectives. The project was "accessible" because it adopted collaborative teaching and learning processes that foster responsibility, honesty, mutual aid, self-confidence, and acceptance of the other. It was "sustainable" by shaping citizens sensitivity to environmental issues and stakeholders on sustainable development but mainly it was "innovative" since it put the focus of the learning process on the students and initiated them in research procedures and processes that promote scientific way of working and thinking "young scientists" and "young investigators."

\section{In the Laboratory of Natural Sciences}

"In teachings that took place in the school science laboratory were applied two educational kits coming from the Environmental Educational Centre of Kastoria and the 
Museum of Natural History "Goulandris" which negotiated the forests' management" (FR). In addition, this laboratory teaching utilized both microscopes and stereoscopes for the material that students collected from the banks of Lake Kastoria, phytoplankton as well as the benthic samples that teachers of the centre collected for use in the program.

Group work in chemistry and biology labs: Specifically: (a) Highlight the function of stomata of leaves - the creation of fresh preparations - observation in microscopes, (b) observation of soil organizations in stereoscopes and highlighting their role, (c) measurements-analyzes of soil samples from the forest ecosystems, (d) data processing-correlation of the field work and laboratory (FR).

Students used scientific keys identifying species and thus perceived the biodiversity of the invisible world and completed an exercise in taxonomy, based on specific criteria and comments.

Partners of the Cornell science inquiry partnerships, in the actions "inquiry moments," sometimes, used the informal, spontaneous conversations to make students think more on what they do and how this relates to broader issues in science (Trautmann et al., 2004). Discussions developed to be expressed various aspects on the experimental design, ways of data collection and interpretation of their results. This way, students do not learn fragmentary science, a series of separate issues, but can develop comprehensive overview of the inquiry issues.

\section{In the Libraries}

According to the strategy of UNECE (2005), ESD must be supported by relevant visual material such as methodological, pedagogical and didactic publications, textbooks, teaching aids and tools, case studies and good practices, special electronic, and other audiovisual sources. In recent years, there has been multiple academic collaborations involving undergraduate students in critical reading of scientific papers, demonstrating its educational value in universities (see for example Henderson and Buising, 2000). Similarly, in schools peer review of articles can provide help focus their research questions, to improve methodology, to think critically about the results, and to improve their scientific background (Carlsen et al., 2001; National Research Council, 2000). This was commented upon by the teachers involved:

In the school library, there was an extensive exploring of the literature on program themes and areas visited. Articles of scientific conferences of EE were read by teachers and students, retrieving details on methodology and ways of application of the project (Teacher 1).

Because of the advantages and disadvantages of online learning, teachers had to embrace very carefully the new experiences that web learning offers (Zanamwe et al., 2013).

\section{In the Field}

Visits, tours, measurements, educational pathways in the natural and artificial ecosystems of Crete, Florina, and Kastoria took place in the field. Before undertaking the fieldwork on the lake's banks in Kastoria, the FR highlighted:

Fission of the team into groups, briefing on forthcoming field activities, presentation of the devices and worksheets and practice in the ways of using them. Recommendations on the approach of countryside and safe behavior of groups were given in every visit (FR).

Similarly, while in the field the FR commented:

The visit to the monastery Epanosifis accompanied with a guide to surroundings and an exploration to historical and religious archives by the abbot of the monastery. During the walk in the monastery forest, recorded the natural condition of the forest, developed discussion on the management, and protection of the forest in the past and worded proposals to Abbot, to Mayor and foresters about fire, grazing, and encroachment area protection (FR).

The work plan of the Greek Pedagogic Institute on "forestenvironment-development" is based on forest field works and contains records of the species of flora (number and age of trees, tree condition, deforestation, etc.), vegetation and animals living in the forest. In addition, includes measurements of abiotic factors (soil, temperature, and humidity), descriptions of human interventions, the forest protection infrastructure for deforestation, waste bins, dropping litter, and indications of the role and usefulness of the forests (PI, 2007). The FR highlighted:

On the walks in the woods of Mount Vitsi and lake-side forest of Kastoria, students wrote down their observations in a special work sheet that EE Center of Kastoria had delivered. They recorded species of the encountered trees, focused on the different forms of leaves and the variety of lake birds, found animal traces, developed correlations between the bio-communities and ecosystems of Crete and Macedonia.... They designed assumed trophic networks, measured physical and chemical parameters (temperature, salinity, $\mathrm{pH}$, turbidity, and oxygen content) with special devices in the water of Lake Kastoria and tried to explain and relate the values to geological factors and human activities.... In the Epanosifis forest, students learned to measure easily the height of the trees with a simple methodology based on the proportions of similar triangles, they used a compass and exercised in reading topographic map in the forest area of Mount Vitsi, they observed birds with telescopes in the visit of Bird Watching Point of Prespes Information Centre (AF).

In addition, one of the participating teachers noted "In the Astritsi gorge, students followed the pathway that had been marked by the previous school environmental team and discussed the interventions made in the past to highlight the area as summer cultural center" (Teacher 3). Students had the opportunity to visit agro-tourism units in different areas and quite distant from each other, and discuss with local entrepreneurs and development actors. "The energy autonomy of the agrotourism unit Selena received particular interest of 
students because of the wind generators used and the conjugate solar park" (Teacher 2). Research itself is a powerful factor in shaping how we construct the nature of subject matter, learning and the implications on teaching practice.

Further, the meaning and significance of an inquiring environmental issue with special scientific or general public importance will tend to vary in both time and space. This means that it will be judged to be both lesser and greater at different times in history as well as in different locations (Robottom, 2004). The FR and participating teachers demonstrated this variance.

- The 4-day visit to Meteora, Kastoria and Florina, and the accommodation in rural resort of Prespes aimed to acquaint everyone with the unique natural environment, historical monuments, and traditional way of life in these regions (AF).

- Eco-guide in St. Achilles guided us to the traditional village of Psarades. A tour was carried out in Prespes guided by the Association for the Protection of Prespes and in Nymfeo by the Arcturus Centre, which protects the wolf and brown bear (Teacher 3).

- The boat ride to the small lakes of Prespa and Skitaria with the rock paintings from the $13^{\text {th }}$ and $14^{\text {th }}$ centuries excited the students as much as the romantic morning walk on the banks of Lake Kastoria and the lakeside forest (Teacher 3).

- Students visited large construction projects, which are missing or exist in a small scale in Crete, such as the Egnatia motorway, the tunnels of motorways, the dam of the river Strymon, the artificial lake Kerkini and special structures such as the floating bridge to St. Achilles inside the small lake Prespa (FR).

Greek Pedagogic Institute proposes the organization of visits to a nearby forest to the school and possibly in another forest that had recently burned; these were activities that were carried out in the program (PI, 2007).

During the trip to North Greece, crossing the mountainous forest areas was given the chance of observation burned forests, which shocked the students. They were stunned because it was first time they saw burnt forest nearby. They saw firewalls, ski tracks, and resorts as protection and development intervention in forest areas (Teacher 3).

\section{The Schoolmates' Company}

The creative company of schoolmates constitutes a fundamental factor and condition of learning in the work groups of young people. It is important for the success of the school educational projects' implementation to utilise, as much as it is possible, the friendships and the way that students have learned to spend time together and share their common interests, "Students learned to exchange of views with active participation to all the phases of the Project" (Teacher 2). Students wrote in their reflection about what they experienced, coming back to Crete from Macedonia "These days will remain forever engraved in our memories, in heart and mind," We wish to live similar experiences in the future, thank you for the opportunity," "nature-person-team."A positive learning environment where one arouses a learner's positive emotions, such as through a fun and interesting learning field day, may be part of the building the sociocultural context. This finding of a fun or an interesting learning environment is also a critical factor to promote students' social interaction with their peers (Wang and Carlson, 2011).

\section{With Local Communities}

The Project made use of the social environment in connection with the local communities. According to Vygotsky (1997), who treated learning as a profoundly social process, he considered that there was no knowledge without social life, that the higher mental functions derived from social life and it was not enough the interaction with the natural environment but also required the social. Indoor and outdoor activities attempted an intergenerational comingling and communication with older people, scientists and experts to find traditional, anti-consumerist and sustainable ways of life (EC, 2007).

An attempt became to open the school in society, to get awareness of the potential development of our region (e.g. through rural tourism programs) with harmonization of human activities with the natural environment, consistently to the local history and cultural heritage, not students abandon their homes (AF).

By assessing the project with what the students wrote on returning from Macedonia, these Science subjects reached in the environmental context by enriching local research on several levels of "community," offering them the satisfaction of doing something useful for the society, associated with the quality of life (Helms, 1998). This was evident in both FR "students to be informed by the Mayor on the policy and interventions that are going to be applied in gorges and other natural ecosystems of the region," and in comments from participating teachers, "students mentioned the problems that they identified in the forest Epanosifi and gorge Astritsi accompanied with proposals for protection and development" (Teacher 3).

\section{DISCUSSION}

Experiential and discovery learning can now be achieved more easily than in the past with internet use and opening web communities (Kartsiotis, 2008; Mokias, 2008). Communication of the program participants was facilitated by the use of ICTs, such as face book, mobiles, blogs, whenever it was not analytically recorded and directly feasible in the studied material. New technologies accelerate data collection, classification and analysis, minimize the time between discovery and application (AAAS, 2013).

Noteworthy is the development of educational theories in recent years that face learning as a process of participation in a community than as an individual process of discovering of the established truth (Wenger, 1998; Carlsen et al., 2001). The choice of open classes in social learning environments, offered experiences to students which brought them face to face 
with questionnaires, evidence, historical knowledge, and real problems, which was missing from their previous experiences. The innovative teaching techniques, as debate, pathways, brainstorming, extended and structured scientific discussions, peer learning activities, presentations, etc., revealed multiple representations of student ideas in variety of issues. Avery and Carlsen (2001) articulated a different view of learning where social participation and community engagement provided the vehicle for science to act in the real world. EE leans toward this direction with its principal objective to engage students in environmental research/inquiry/discovery as practicing in the real world (Meyer and Avery, 2001).

In a similar course developed by the Colorado Department of Education in 2012, it used an interdisciplinary approach in the classroom combined with an experiential learning experience (CEEP, 2012). Each high school student got to live with a Colorado farm or ranch family for one week experiencing and learning about agriculture first hand. Agricultural and environmental topics such as water, governmental regulations, wildlife issues, economics of farming and labor, farm worker issues were covered, additionally so were academic areas of History, Geography, Civics, and Economics. This experience demonstrated that the farm stay was a powerful learning experience for suburban students.

As ESD is locally relevant and culturally appropriate, based on local needs, perceptions, and conditions, recognizing and fulfilling local needs with global effects and consequences, ESD is not "one size fits all," but must be created to account for regional and local differences (Opertti, 2009). Science teachers, in collaboration with the school's specialist, can involve parents and other adults in several ways, broadening the social context of the classroom. It is also important for teachers to recognize that much of what their students learn informally is often wrong, incomplete, poorly understood, or misunderstood, and that basic education can help students to reconstruct this knowledge and acquire new learning. Teachers should design the learning environments of today's schools to encourage students to learn actively, cooperate with other students, and work meaningfully with authentic materials (Vosniadou, 2001).

\section{CONCLUSION}

This research aimed to bring out and clarify those characteristics of the learning environments, which make open classes in society effective and sufficient. The studied SPEE was designed to open the school to the local communities of North and South Greece, with many and varied activities inside and outside the school, by targeting the protection and sustainable management of natural and artificial ecosystems. A spherical vision of curriculum should include learning outcomes to achieve pedagogical and instructional strategies linked to teaching and learning, teaching materials for teachers and students, the discipline's contents, evaluation of learning outcomes, and achievements, with curriculum management (Opertti, 2009).
By implementing DTM in the environmental projects, teachers supplied the students with focused questions and urged them to try to find answers, more specifically, facilitated students as coresearchers to choose their own issues, to set the queries and decide about the best methods for inquiry (Trautmann et al., 2004). Students who learned by inquiry, constructed gradually the knowledge by themselves, submitted scientifically oriented questions, designed studies, used appropriate tools, and techniques to gather data, formulated explanations of relevant factors to evaluate their opinions on alternative solutions, justified the proposed explanations, communicated, presented and discussed data and results (NRC, 2000). In addition, this type of school projects had significant implications on teachers' training, which is even more useful until educational institutions review their programs to accommodate ESD in the learning content. Through this project, the involved teachers became properly trained and seasoned advocates of sustainability (Ojedokun, 2012).

\section{REFERENCES}

American Association for the Advancement of Science (AAAS). (2013) Science for All Americans: Online. Available from: http://www. project2061.org/publications/sfaa/online/chap1.htm. [Last accessed on 2017 Jun 28].

Avery, M.L., \& Carlsen, S.W. (2001). Knowledge, Identity, and Teachers' Multiple Communities of Practice. St. Louis, MO: Paper Presented at the Annual Meeting of the National Association for Research in Science Teaching, March, 25-28. Available from: http:/ei.cornell.edu/pubs. [Last accessed on 2017 Jun 28].

Bruner, J. (1960). The process of education. A Penetrating Research on School Education that Breaks New Ground in Learning and Teaching. Translate Clerides Ch. Publisher Karavia.

Bell, J. (1997). Doing Your Research Project. Buckingham: Open University Press.

Callisto. (2008). Guide for the Implementation of Programs of Open Environmental Classes 'Callisto'. Athens: Greek Ministry of Education and Religious Affairs. Available from: http://www.e-yliko.gr. [Last accessed on 2017 Jun 28].

Carlsen, W.S., Cunningham, C.M., \& Trautmann, N.M. (2001). Peer Review by School Science Students: Its Role in Scientific Inquiry. Paper presented at the Annual Meeting of the National Association for Research in Science Teaching. St. Louis, MO. March 25-28, 2001. Available from: http://www.ei.cornell.edu/pubs.

Chrisafidis, K. (2006). Communicative-Experiential Teaching, The Introduction of the Project in School. Athens: Gutenberg.

Colorado Environmental Education Plan (CEEP). (2012). A Roadmap to Develop Graduates with the Skills and Understanding of the Outdoor Environment, Colorado Department of Education. Denver, CO: Colorado Department of Education. Available from: http://www.yvsc.org/wpcontent/uploads/2012/11/ColoradoEnvironmentalEducationPlan.pdf. [Last accessed on 2017 Jun 28].

Cohen, L., \& Manion, L. (1994). Research Methods in Education. $4^{\text {th }}$ ed. London: Routledge.

Doise, W., \& Mugny, G. (1984). The Social Development of the Intellect. New York: Pergamon.

European Commission (EC). (2007). Working Document of the Commission Services 'Schools for the $21^{\text {st }}$ Century'. Brussels: European Commission.

Espinosa-Bueno, J., Labastida-Pina, S., Padilla-Martínez, K., \& Garritz, A. (2011). Pedagogical content knowledge of inquiry: An instrument to assess it and its application to high school in-service science teachers. US-China Education Review, 8(5), 599-614.

Frey, K. (1986). The Method of Project. Thessaloniki: Kiriakidis.

Gallagher, J., Wheeler, C., Mcdonough, M. \& Namfa, B. (2000). Sustainable Environmental Education for a Sustainable Environment: Lessons from Thailand for Other Nations, Water, Air, and Soil Pollution. Netherlands: 
Kluwer Academic Publishers.

Greek Ministry of Education. (2007). 117302/C7/19-10-2007 with the Subject of Designing of School Educational Programs. Athens: Ministry of Education and Religious.

Helms, J.V. (1998). Science and/in the community: Context and goals in practical work. International Journal of Science Education, 20, 643-653.

Henderson, L., \& Buising, C. (2000). A peer-reviewed research assignment for large classes. Journal of College Science Teaching, 30(2), 109-113.

Iosifidis, T. (2003). Analysis of Qualitative data in Social Sciences. Athens: Kritiki Publications.

Iosiphides, T., \& Spyridakis, M. (2006). Qualitative Social Research, Methodological approaches and analysis. Athens: Kritiki Publications.

Kalathaki, M. (2013). Evaluation tool for the environmental programs of Greek secondary education through the prism of education for the sustainable development. Journal US-China Education Review A and $B, 3(7), 557-565$.

Kalathaki, M. (2015). Evaluation tool for the application of discovery teaching method in the Greek environmental school projects. World Journal of Education, 5(2), 40-51.

Kartsiotis, T. (2008). Safe Use-Educational Use of the Internet. Available from: http://www.dart.gov.gr/files/thessaloniki/230208/230208_PSD_ kartsiotis.pdf.

Komis, B. (1999). The Influence of the Social Environment. Available from: http://www.csd.uoc.gr/ hy402/lectures_transp/theories_mathishs_kai ypologistes $2 /$ tsld023.htm.

Komis, B. (2004). Introduction to Educational Applications of Information and Communication Technologies. Athens: New Technologies Publications.

Mandrikas, A., Parkosidis, I., Stoumpa, A., Antonopoulou, M., Tsilidis, M., Chalkidis, A., \& Skordoulis, K. (2005). Teaching Proposal for Teacher Education for Sustainability: The Case of Air Pollution. Paper Presented at the $4^{\text {th }}$ Congress of Pan-Hellenic Union of Teachers for the Environmental Education, Nafplio, Greece.

Meyer, Z.D., \& Avery, M.L. (2001). A Science and Technology Studies Lens for Studying Teacher Practice. Paper Presented at the Annual Meeting of the American Educational Research Association, Seattle, WA, April, 12. Available from: http://www.ei.cornell.edu/pubs. [Last accessed on 2017 Jun 28].

Mokias, I. (2008). Theories of Learning and Development of Teaching Situations, the Role of ICTs in Schools. Available from: http://www. epimorfosi.pblogs.gr/files/137258. [Last accessed on 2017 Jun 28].

National Research Council (NRC). (2000). Inquiry and the National Science Education Standards. Washington, D.C.: National Academy Press.

New School. (2010). The New School Framework. Available from: http:// www.pi-schools.gr. [Last accessed on 2017 Jun 28].

Ojedokun, O. (2012). Diffusing education for sustainability into teacher education programme in Nigeria: A theory in use. World Journal of Education, 2(2), 109-119.

Opertti, R. (2009). Training Guideline on Incorporating ESD in the Curriculum. Regional Workshop on the Thematic Issues in Education for Sustainable Development (ESD) under the Mobile Training Team (MTT) Project, 1-5 June 2009, Bangkok, Thailand. Available from: http://www.ibe.unesco.org/fileadmin/user_upload/COPs/News documents/2009/0905Bangkok/ESD Presentation. pdf.

Pedagogical Institute. (2007). Forest-Development-Environment: Indicative Work Plan for Primary Education. Available from: http://www.pischools.gr/drast/perivalontiki. [Last accessed on 2017 Jun 28].

Robottom, I. (2004). Constructivism in environmental education: Beyond conceptual change theory. Australian Journal of Environmental Education, 20(2), 93-101.

Rogers, A. (1998). Adult Education. Athens: Routledge.

Trautmann, N., MaKinster, J., \& Avery, L. (2004). What Makes Inquiry so Hard? (and Why is it Worth it?) Proceedings of the NARST 2004 Annual Meeting (Vancouver, BC, Canada), National Association for Research in Science Teaching (NARST), April 1-3.

UNECE. (2005). UNECE Strategy for Education for Sustainable Development adopted at the High Level Meeting of Environment Ministers and Education, Vilnius, March, 17-18.

Vare, P., \& Scott, W. (2007). Learning for a change: Exploring the relationship between education and sustainable development. Journal of Education for Sustainable Development, 1(2), 191-198.

Vosniadou, S. (2001). How Students Learn. Washington, DC: International Education Office of UNESCO, International Academy of Education.

Vygotsky, L.S. (1997). Mind in Society, The Development of Higher Psychological Processes (Translated by Bibbou, A., Vosniadou, S). Athens: Gutenberg.

Wang, H.H., \& Carlson, S.P. (2011). Factors that influence student's satisfaction in an environmental field day experience. International Electronic Journal of Environmental Education, 1(2), 129-139.

Wenger, E. (1998). Communities of Practice: Learning, Meaning, and Identity. Cambridge: Cambridge University Press.

Zanamwe, N., Rupere, T., \& Kufandirimbwa, O. (2013). Use of social networking technologies in higher education in zimbabwe: A learners' perspective. International Journal of Computer and Information Technology, 2(1), 8-18.

Zygouri, E. (2005). Evaluation of Environmental Education Programs: Theory and Practice. Athens: Tipothito. 